\title{
BMJ Open Long-term outcomes in patients newly diagnosed with iron deficiency anaemia in general practice: a retrospective cohort study
}

\author{
Annemarie Schop (D) , ${ }^{1}$ Karlijn Stouten, ${ }^{2}$ Jurgen Riedl, ${ }^{2}$ Ron van Houten, ${ }^{3}$ \\ Joost van Rosmalen, ${ }^{4}$ Frank Wolfhagen, ${ }^{5}$ Patrick J E Bindels, ${ }^{6}$ Mark-David Levin ${ }^{1}$
}

To cite: Schop A, Stouten K, Riedl J, et al. Long-term outcomes in patients newly diagnosed with iron deficiency anaemia in general practice: a retrospective cohort study. BMJ Open 2019;9:e032930. doi:10.1136/ bmjopen-2019-032930

- Prepublication history for this paper is available online. To view these files, please visit the journal online (http://dx.doi org/10.1136/bmjopen-2019032930).

Received 31 July 2019 Revised 29 0ctober 2019 Accepted 31 October 2019

\section{Check for updates}

(C) Author(s) (or their employer(s)) 2019. Re-use permitted under CC BY-NC. No commercial re-use. See rights and permissions. Published by BMJ.

For numbered affiliations see end of article.

Correspondence to Dr Annemarie Schop; a.schop2@asz.nl

\section{ABSTRACT}

Objectives To describe all iron deficiency anaemia (IDA)-related causes during follow-up of patients newly diagnosed with IDA and to assess whether a delayed colorectal cancer (CRC) diagnosis influences survival. Design and setting Retrospective cohort study of patients from general practices in the Dordrecht area, the Netherlands.

Participants Men and women aged $\geq 50$ years with a new diagnosis of IDA (ie, no anaemia 2 years previously). Method From February 2007 to February 2018, all relevant data were collected from the files of the referral hospital. Early IDA-related cause was defined as established within 18 weeks after IDA diagnosis. Cox proportional-hazards regression was used to analyse survival of patients with CRC diagnosis.

Results 587 patients with IDA were included with a median follow-up of 4.6 years. Early and late IDA-related causes could be established in $32 \%$ and $8 \%$ of patients, respectively. Early and late CRC was found in $8 \%$ and $2 \%$ of patients, respectively, and were located mainly right sided. After adjustment for age, gender and TNM classification, mortality risk was lower in patients with IDA with early CRC diagnosis, but not significantly (HR 0.30 , $95 \% \mathrm{Cl} 0.09$ to 1.02 ).

Conclusion Even with extended follow-up, the cause of IDA remains elusive in the majority of patients with IDA in general practice. However, patients with IDA are at increased risk for in particular right-sided CRC and a late diagnosis of CRC appears to have a detrimental effect on survival in patients with IDA.

\section{INTRODUCTION}

Around $5 \%-10 \%$ of patients with iron deficiency anaemia (IDA) have colorectal cancer (CRC) and, therefore, endoscopic evaluation is advised. ${ }^{1-5}$ However, most studies reporting on IDA and CRC only included patients already referred for endoscopic evaluation. Information on general practice patients diagnosed with IDA and not referred for endoscopic evaluation is scarce. So far, only two cohort studies have included patients from the moment of IDA diagnosis
Strengths and limitations of this study

- Large cohort of patients diagnosed with iron deficiency anaemia (IDA) with exclusion of patients known with anaemia 2 years previously.

- Long period of follow-up concerning survival and the most relevant outcome, namely IDA-related hospital diagnoses.

- Limited information concerning IDA-related diagnoses made out-of-hospital.

- Number of events (colorectal cancer) limits the survival analysis of (late) colorectal cancer.

in general practice. ${ }^{67}$ These studies reported that a third of patients with IDA diagnosed in general practice receive an endoscopic evaluation within several weeks after IDA diagnosis. Of these patients with IDA, the incidence of CRC was $4.6 \%$ and $5.9 \%$, respectively. ${ }^{67}$ During follow-up of patients with IDA, including those who were not endoscopically evaluated, an additional $3.2 \%$ (follow-up of 3 years) and $2.4 \%$ (follow-up of 1 year) of patients were diagnosed with CRC. ${ }^{67}$ Limited data are available for the group of patients who do not receive an endoscopic evaluation and for whom other underlying causes related to IDA might be diagnosed later on. Furthermore, it is unknown whether the 3\% of general practice patients with IDA who have a delayed CRC diagnosis have a poorer overall survival.

This study investigated a cohort of general practice patients with a new laboratory diagnosis of IDA. For the entire cohort, all IDA-related diagnoses made in-hospital are described during extended follow-up. Furthermore, we analysed the characteristics of patients with a CRC diagnosis, and the association between a delayed CRC diagnosis and overall survival. 


\section{METHOD}

\section{Patient and public involvement}

This study has been retrospectively conducted in a cohort of patients formed by general practitioners (GPs) participating in a large project on anaemia evaluation improvement. ${ }^{8}$ Therefore, the patients' involvement has been limited. Patients were informed about this project by their treating GP. Data about these patients were processed anonymously. The participating GPs were informed about the study results and encouraged to give feedback.

\section{Study population}

The laboratory system of the Albert Schweitzer Hospital started a project to improve anaemia evaluation in general practice on 1 February 2007, in which 81 of the invited 150 GPs (in the Dordrecht area, the Netherlands) agreed to participate. Every time the participating GPs requested a blood test for their patients aged $\geq 50$ years and this revealed a low haemoglobin concentration, a comprehensive laboratory assessment was performed. This laboratory protocol consisted of measurement of haemoglobin, mean corpuscular volume (MCV), C reactive protein and/or erythrocyte sedimentation rate, vitamin $\mathrm{B}_{12}$, creatinine, ferritin, folic acid, lactate dehydrogenase, transferrin, reticulocytes, leucocytes, thrombocytes and serum iron.

IDA was defined as haemoglobin $<13.7 \mathrm{~g} / \mathrm{dL}$ for men and $<12.1 \mathrm{~g} / \mathrm{dL}$ for women in combination with ferritin $<25 \mu \mathrm{g} / \mathrm{L}$ for men and $<20 \mu \mathrm{g} / \mathrm{L}$ for women. ${ }^{9}$ The participating GPs were provided with the laboratory results for each patient, including an interpretation of the laboratory diagnosis of IDA, and they were advised to request endoscopic evaluation for their patient. Fast-track endoscopic evaluation places (ie, within 4 weeks) were available for these patients.

Retrospectively, we selected a cohort of patients from the anaemia improvement project who presented with a new laboratory diagnosis of IDA during the period 1 February 2007 until 1 February 2016 and collected additional clinical information. We excluded patients who were already known with anaemia in the previous 2 years.

\section{Data collection}

Clinical data were extracted (if available) from the electronic medical files of the Albert Schweitzer Hospital. Collected clinical information consisted of endoscopic evaluations performed within 18 weeks after IDA diagnosis and all IDA-related causes established in-hospital including the date of the IDA-related diagnosis. Other diagnostic investigations to evaluate IDA and/or endoscopic evaluations performed 18 weeks after IDA diagnosis were not collected. CRC and other IDA-related malignancies were checked for registration in the Netherlands Comprehensive Cancer Organization. ${ }^{10}$ The location of CRC was verified using pathology and operation reports and divided into either right (ie, colon ascendens, caecum and transversum) or left (ie, sigmoid, colon descendens and rectum). The stage of CRC was registered using the TNM 5 classification. ${ }^{11}$ The length of follow-up was variable since patients were selected over a 9-year period (2007-2016). The end of follow-up was defined as the date of death or the last noted hospital record before 1 February 2018 to ensure a follow-up time of at least 2 years.

\section{Definitions}

Early endoscopic evaluation was defined as all full endoscopies (ie, gastroscopy and colonoscopy) and colonoscopies performed within 18 weeks after establishment of IDA. Gastroduodenoscopy alone was only counted as early endoscopic evaluation if an IDA-related diagnosis according to the Dutch anaemia guideline was found. ${ }^{9}$

Early IDA-related cause was defined as all in-hospital registered causes within 18 weeks after the establishment of IDA. Late IDA-related cause was defined as all in-hospital registered causes defined 19 weeks or later after the establishment of IDA.

The IDA-related causes were divided into four categories. The first category was defined as all gastrointestinal (GI) malignancies and those with a strong suspicion of GI malignancy but no pathological proof. The second category was defined as other malignancies causing IDA (ie, urothelial or endometria carcinoma) and patients with a GI metastasis of a non-GI primary tumour. The third category was defined as benign GI causes of IDA, which included angiodysplasia, gastritis/erosions, ulcers, haemorrhoids, polyps $\geq 1 \mathrm{~cm}$, coeliac disease, Crohn's disease and radiation proctitis. Finally, the fourth category was defined as all other non-GI causes of IDA that included in-hospital registration of repetitive blood donation, hypermenorrhoea, low-iron diet and severe epistaxis as cause of IDA.

\section{Statistical analysis}

All patients with IDA were divided into either early or no (early) endoscopic evaluation and the data were characterised with standard descriptive statistics. Chi-square tests and Mann-Whitney U tests were used to compare patients receiving endoscopic evaluation and patients without endoscopic evaluation. Univariable and multivariable logistic regression analysis was performed with CRC diagnosis (yes/no) as dependent variable. In these logistic regression analyses, the independent variables were age, haemoglobin, ferritin, gender (male/female) and MCV (microcytic or normocytic/macrocytic anaemia). Interaction effects between gender and haemoglobin and between gender and ferritin were tested, but not included in the final model as they were not statistically significant. The goodness-of-fit of the multivariable logistic regression was assessed using the Hosmer-Lemeshow test. A Cox proportional-hazards regression analysis was performed including only those patients who received a CRC diagnosis during follow-up. In the Cox regression, the time at risk was the time from CRC diagnosis until death, or to the end of follow-up. In the Cox regression, the independent variables were age, gender (male/female), early or late 
Table 1 Baseline characteristics of the 587 patients in general practice with iron deficiency anaemia (IDA)

\begin{tabular}{|c|c|c|c|c|c|}
\hline & $\begin{array}{l}\text { IDA cohort } \\
n=587(100 \%)\end{array}$ & $\begin{array}{l}\text { Early endoscopic } \\
\text { evaluation } \\
\mathrm{n}=211(36 \%)\end{array}$ & $\begin{array}{l}\text { No early endoscopic } \\
\text { evaluation } \\
n=376(64 \%)\end{array}$ & $P$ value & $\begin{array}{l}\text { Reference } \\
\text { value }\end{array}$ \\
\hline Age in years & $68(50-101)$ & 69 (50-95) & $66(50-101)$ & 0.207 & \\
\hline Gender & & & & $<0.001$ & \\
\hline Male & $212(36 \%)$ & $100(47 \%)$ & $112(30 \%)$ & & \\
\hline Female & $375(64 \%)$ & $111(53 \%)$ & 264 (70\%) & & \\
\hline \multicolumn{6}{|l|}{ Haemoglobin, g/dL } \\
\hline Male & $12.3(5.3-13.5)$ & $10.6(5.3-13.5)$ & $12.8(5.8-13.5)$ & $<0.001$ & $13.7-17.7$ \\
\hline Female & $10.8(4.0-11.9)$ & $10.2(4.5-11.9)$ & $11.1(4.0-11.9)$ & $<0.001$ & $12.1-16.1$ \\
\hline$M C V, f L$ & $82(55-102)$ & 79 (55-96) & $83(58-102)$ & $<0.001$ & 82-98 \\
\hline $\mathrm{ESR}, \mathrm{mm} / \mathrm{h}^{*}$ & $20(2-120)$ & $23(4-118)$ & $20(2-120)$ & 0.015 & $<35$ \\
\hline $\mathrm{C}$ reactive protein, $\mathrm{mg} / \mathrm{L} \dagger$ & $<5(<5-144)$ & $<5(<5-71)$ & $<5(<5-144)$ & $<0.001$ & $<10$ \\
\hline \multicolumn{6}{|l|}{ Ferritin, $\mu \mathrm{g} / \mathrm{L}$} \\
\hline Male & $10(2-24)$ & $9(2-24)$ & $11(2-23)$ & $<0.001$ & $25-250$ \\
\hline Female & $7(1-19)$ & $7(1-19)$ & $8(1-19)$ & 0.055 & $20-250$ \\
\hline Iron saturation, \%‡ & $7(2-55)$ & $6(2-22)$ & $7(2-55)$ & $<0.001$ & $20-60$ \\
\hline \multicolumn{6}{|l|}{ Serum iron, $\mu \mathrm{mol} / \mathrm{L}$} \\
\hline Male & $6.2(1.9-22.1)$ & $4.5(1.9-22.1)$ & $7.4(2.0-21.0)$ & $<0.001$ & $14-28$ \\
\hline Female & $5.0(1.6-42.5)$ & $3.9(1.9-17.6)$ & $5.3(1.6-42.5)$ & 0.001 & $10-25$ \\
\hline Transferrin, g/L & $3.36(1.97-4.74)$ & $3.38(2.38-4.74)$ & $3.34(1.97-4.74)$ & 0.043 & $2.00-3.60$ \\
\hline
\end{tabular}

*Missing values $n=157$.

†Missing values $n=3$.

$\ddagger$ Missing values $n=38$. Values are median (range). Measured laboratory values are at point of IDA diagnosis. The $p$ value compares the baseline characteristic of patients with and those without an early endoscopic evaluation.

ESR, erythrocyte sedimentation rate; MCV, mean corpuscular volume.

CRC diagnosis, and stage of CRC (I, II, III, IV or unknown stage). The proportional-hazards assumption was tested by including interactions of independent variables and follow-up time in a Cox regression with time-dependent covariates. The location of CRC was compared between patients with an early or late diagnosis using a $\chi^{2}$ test.

Data were analysed using SPSS for Windows, V.24. All statistical tests were two-sided and a $p$ value $<0.05$ was considered statistically significant.

\section{RESULTS}

\section{Cohort description}

Between 1 February 2007 and 1 February 2016, a total of 587 patients aged $\geq 50$ years with a new laboratory diagnosis of IDA were included, consisting of 212 (36\%) men and 375 (64\%) women. The median haemoglobin concentration was 12.3 (range, 5.3-13.5) g/dL and 10.8 (range, 4.0-11.9) g/dL and the median ferritin level was 10 (range, 2-24) $\mu \mathrm{g} / \mathrm{L}$ and 7 (range, 1-19) $\mu \mathrm{g} / \mathrm{L}$ for men and women, respectively. Basic characteristics (age, gender and laboratory values at point of IDA diagnosis) are presented in table 1.

\section{Early endoscopic evaluation}

Of all 587 general practice patients diagnosed with IDA, $211(36 \%)$ had an early endoscopic evaluation, consisting of $45(21 \%)$ colonoscopies, $154(73 \%)$ full endoscopies and $12(6 \%)$ gastroscopies. The median time for early endoscopic evaluation was 5 weeks (IQR 2-7 weeks). Patients receiving endoscopic evaluation versus those who did not receive early endoscopy were significantly different in terms of laboratory values and gender, but not in age (table 1). In $115(55 \%)$ of the 211 patients, who received an early endoscopic evaluation, a GI-related diagnosis could be made.

\section{IDA-related causes}

Median time of follow-up for the entire cohort was 4.6 (IQR 2.6-7.0) years, during which an IDA-related cause could be made in 234 (40\%) patients, consisting of 190 $(32 \%)$ early causes and $44(8 \%)$ late causes. However, in 353 patients $(60 \%)$, no IDA-related cause was found during the entire follow-up period (figure 1). In 18 patients, more than one IDA-related cause was established resulting in 254 in-hospital registered causes of IDA (table 2). Other causes (34\%) and benign GI causes $(35 \%)$ were the most common categories. An early 


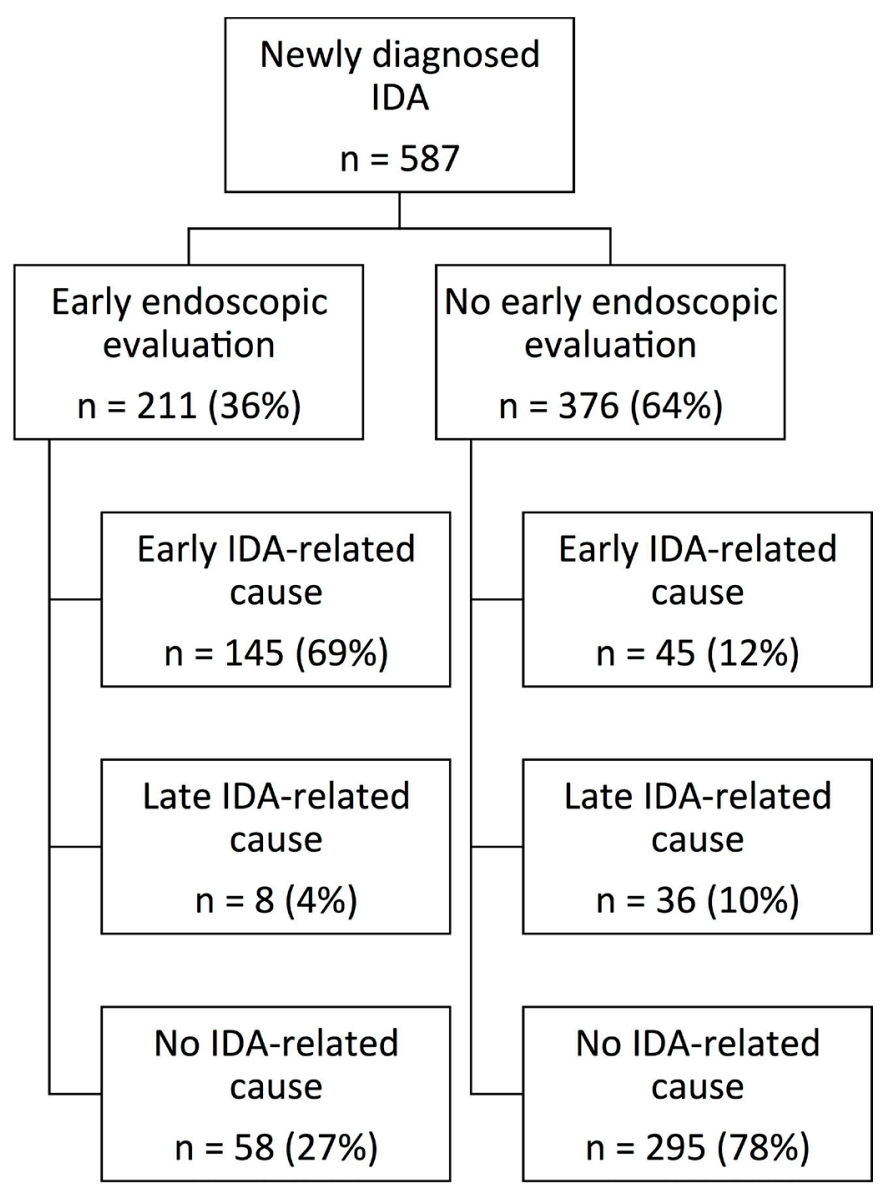

Figure 1 Flowchart of the cohort with iron deficiency anaemia (IDA).

malignant cause for IDA was found in 59 patients (10\%), of whom 49 had CRC. An additional 21 patients (4\%), of whom four received an early endoscopic evaluation without abnormalities, were diagnosed with a malignant cause for IDA later on, consisting of 12 CRC.

\section{Colorectal cancer}

Of the 587 patients with IDA, 61 (10\%) received a diagnosis of CRC during the study period (ie, 49 early and 12 late CRC diagnoses). In four patients, two separate tumours were diagnosed in the colon, and one patient presented with three different colon tumour locations. The CRC was right sided in 41 of 49 patients (84\%) with an early diagnosis and in 8 of 12 patients $(67 \%)$ with a late CRC diagnosis $(\mathrm{p}=0.184)$. Older age (OR 1.03; 95\% CI 1.00 to 1.05 ), male gender (OR 2.12; $95 \%$ CI 1.18 to 3.79 ), lower haemoglobin concentrations (OR 1.27; $95 \%$ CI 1.08 to 2.49 ) and microcytic anaemia (OR 2.63; $95 \%$ CI 1.30 to 5.31) showed a significant association with CRC diagnosis (table 3 ).

The 61 patients with CRC diagnosis had a median follow-up of 4 years (range, 5 weeks to 10.7 years) from the moment of CRC diagnosis; during this period, 19 patients $(31 \%)$ died. No significant violations of the proportionalhazards assumption of the Cox regression were detected in patients with CRC diagnosis. After correction for age, gender and the TNM classification at the moment of CRC diagnosis, mortality risk was lower, but not significant, in the group of patients with an early CRC diagnosis (HR $0.30 ; 95 \%$ CI 0.09 to 1.02 ) (table 4 ).

\section{DISCUSSION \\ Principal findings}

In this large retrospective cohort study, an early endoscopic evaluation was done in a third of newly diagnosed patients with IDA, and these patients were more often male gender and had more severe laboratory abnormalities. The most common category if IDA-related causes established in this cohort were benign GI causes $(35 \%)$. However, in the majority of patients $(60 \%)$, no in-hospital IDA-related cause could be found during the median follow-up of 4.6 years. In addition, there were $8 \%$ early and $2 \%$ late CRC diagnoses. A CRC diagnosis was associated with older age, male gender, lower haemoglobin concentrations and microcytic anaemia. In addition, some evidence was found for increased survival in patients with IDA with an early CRC diagnosis adjusted for age, gender and TNM classification, but this association was not statistically significant.

\section{Strengths and limitations of this study}

Inclusion of patients in our cohort occurred after an anaemia diagnosis was established in the laboratory. The GPs' reason for laboratory testing was not known. It could have been either specific symptoms in a patient or routine testing for other indications. Still, a diagnostic work-up should start after an IDA is established according to the Dutch GP guideline. This is a well-defined moment in practice.

The participating GPs usually referred their patients to the associated hospital; however, some patients may have preferred referral to a different hospital resulting in an underestimation of the amount of endoscopic evaluations and IDA-related causes. However, since almost all patients in our cohort had an electronic record in the associated hospital, this limits the possibility of missed cases. Furthermore, the two nearest hospitals, both outside the Dordrecht region, had a longer waiting time for endoscopic evaluation compared with the fast-track places we offered the participating GPs. The fast-track places that were offered to the participating GPs during the study period might have led to an increase in early endoscopic evaluations and thereby an increased early IDA-related diagnoses. However, the rate of early endoscopic evaluation was comparable with existing literature and therefore the fast-track places very likely did not affect the study results. ${ }^{67}$

Another aspect that we were unable to monitor was the possibility of consciously refraining from endoscopic evaluation by the GP and/or the patient. One study found that endoscopic evaluation in patients aged $\geq 85$ years is safe and enables a high rate of diagnoses and therapeutic modifications. ${ }^{12}$ Nevertheless, comorbidities, age 
Table 2 Iron deficiency anaemia (IDA)-related causes

\begin{tabular}{|c|c|c|c|c|c|}
\hline & \multicolumn{2}{|c|}{ Early endoscopic evaluation } & \multicolumn{2}{|c|}{ No early endoscopic evaluation } & \multirow[b]{2}{*}{ Total } \\
\hline & Early cause & Late cause & Early cause & Late cause & \\
\hline GI malignancies & & & & & $74(29 \%)$ \\
\hline Colon & 48 & 1 & $1^{*}$ & 11 & \\
\hline Gastric & 3 & & & 1 & \\
\hline Oesophagus & 2 & & & & \\
\hline Small bowel & 1 & & & & \\
\hline Strong suspicion of Gl malignancy & & 1 & 1 & 4 & \\
\hline Other malignancies & & & & & $6(2 \%)$ \\
\hline Urothelial & & 1 & 1 & 1 & \\
\hline GI metastasis of a non-Gl primary & 2 & 1 & & & \\
\hline \multicolumn{6}{|l|}{ tumour } \\
\hline Other causes $\uparrow$ & 36 & 3 & 43 & 4 & $86(34 \%)$ \\
\hline Benign Gl causes & & & & & $88(35 \%)$ \\
\hline Angiodysplasia & 16 & 2 & & 5 & \\
\hline Gastritis/erosions & 19 & 1 & & 4 & \\
\hline Ulcersł & 10 & & & & \\
\hline Haemorrhoids & 4 & & 2 & & \\
\hline Polyps $>1 \mathrm{~cm}$ & 13 & 1 & & 3 & \\
\hline Coeliac/Crohn/ulcerative colitis & 4 & & & 3 & \\
\hline Radiation proctitis & 1 & & & & \\
\hline Total no of IDA-related causes & 159 & 11 & 48 & 36 & $254(100 \%)$ \\
\hline
\end{tabular}

*Diagnosis made on the basis of surgery for colon perforation.

†Other causes included repetitive blood donation, hypermenorrhoea, low-iron diet and severe epistaxis.

‡lncluding gastric ulcers as a result of Helicobacter pylori infection.

GI, gastrointestinal.

and limited life expectancy may still be reasons to refrain from endoscopic evaluation. We did not collect data on other diagnostic investigations and/or endoscopic evaluations performed more than 18 weeks after IDA diagnosis. However, we did document all IDA-related diagnoses made in-hospital during follow-up and some diagnoses, especially non-GI related, were made by means of other investigations than endoscopic evaluation.

It is important to realise that, in the present study, all diagnoses made during follow-up were registered in-hospital. A limitation is that the IDA-related causes found by the GP are not registered and, therefore, might be underestimated. However, the most relevant IDA-related causes, mainly GI-tract related, require in-hospital investigations, which makes the incidence of these causes found in our cohort reliable. In addition, the most worrying outcome is IDA-related malignancy; therefore, we registered these diagnoses from the Netherlands Comprehensive Cancer Organization. This organisation covers the entire Dutch population regarding cancer registrations, and therefore this ensures full representation of IDA-related malignancies. Finally, the survival analysis provided some evidence for an association between early CRC diagnosis and decreased mortality; however, lead-time bias may still be present. A more detailed analysis with a larger cohort is required to confirm our hypothesis of increased overall survival in patients with early CRC diagnosis.

\section{Comparison with existing literature}

In the present study, a third of newly diagnosed patients with IDA in general practice received early endoscopic evaluation; this is in line with others. ${ }^{67}$ Patients with IDA receiving early endoscopic evaluation are more often men. In the Netherlands, CRC has a higher incidence among men compared with women. ${ }^{13}$ This might have stimulated GPs to perform more endoscopies in men. In addition, if women presented with hypermenorrhea, GPs may not have made an initial endoscopic evaluation or a hospital referral. Furthermore, patients with IDA with early endoscopic evaluation had more severe laboratory abnormalities. Some GPs will have a different policy in case of marginal anaemia, that is, these patients might first be treated with iron supplementation before GPs decide to refer for endoscopic evaluation.

This study shows, for the first time, that a small proportion of the IDA-related causes is made by means of investigations other than endoscopy. These diagnoses were mainly non-GI causes, including blood donation and 
Table 3 Logistic regression analysis comparing patients with olorectal cancer (CRC) to those without CRC

\begin{tabular}{|c|c|c|c|c|c|c|}
\hline & \multirow{2}{*}{$\begin{array}{l}\text { CRC diagnosis } \\
\mathrm{n}=61\end{array}$} & \multirow{2}{*}{$\begin{array}{l}\text { No } C R C \text { diagnosis } \\
n=526\end{array}$} & \multicolumn{2}{|c|}{ Univariable analysis } & \multicolumn{2}{|c|}{ Multivariable analysis } \\
\hline & & & OR $(95 \% \mathrm{Cl})$ & $P$ value & OR $(95 \% \mathrm{Cl})$ & $P$ value \\
\hline Age, median (range) & 75 (50-89) & $66(50-101)$ & $\begin{array}{l}1.03 \text { (1.01 to } \\
1.03)\end{array}$ & 0.002 & 1.03 (1.00 to 1.05$)$ & 0.027 \\
\hline \multicolumn{7}{|l|}{ Gender } \\
\hline Male & $28(5 \%)$ & $184(31 \%)$ & Reference group & & 2.12 (1.18 to 3.79$)$ & 0.012 \\
\hline Female & $33(6 \%)$ & $342(58 \%)$ & $\begin{array}{l}0.63(0.37 \text { to } \\
1.08)\end{array}$ & 0.095 & Reference group & \\
\hline $\begin{array}{l}\text { Haemoglobin }(\mathrm{g} / \mathrm{dL})^{*} \text {, } \\
\text { median (range) }\end{array}$ & $9.3(4.5-12.9)$ & $11.3(4.0-13.5)$ & $\begin{array}{l}1.41(1.23 \text { to } \\
1.58)\end{array}$ & $<0.001$ & 1.27 (1.08 to 1.49$)$ & 0.007 \\
\hline $\begin{array}{l}\text { Ferritin }(\mu \mathrm{g} / \mathrm{L})^{*} \text {, median } \\
\text { (range) }\end{array}$ & $7(1-22)$ & $9(1-24)$ & $\begin{array}{l}0.94(0.89 \text { to } \\
1.00)\end{array}$ & 0.052 & 1.01 (0.93 to 1.09$)$ & 0.844 \\
\hline \multicolumn{7}{|l|}{ MCV category } \\
\hline $\begin{array}{l}\text { Normocytic/ } \\
\text { macrocytic } † \text { (MCV } \\
80-102 \text { fL) }\end{array}$ & $20(3 \%)$ & $349(60 \%)$ & Reference group & & Reference group & \\
\hline Microcytic (MCV <80fL) & $41(7 \%)$ & $177(30 \%)$ & $\begin{array}{l}4.04(2.30 \text { to } \\
7.11)\end{array}$ & $<0.001$ & $2.63(1.30$ to 5.31$)$ & 0.007 \\
\hline
\end{tabular}

${ }^{*}$ Analysed as continuous variables. ORs should be interpreted as the effect of 1-unit decrease in concentration for haemoglobin and 1-unit increase in concentration of ferritin.

†Three patients had an MCV value $>100 \mathrm{fL}$ at the time of IDA diagnosis.

IDA, iron deficiency anaemia; MCV, mean corpuscular volume.

hypermenorrhoea (despite applying a 50-year cut-off to prevent hypermenorrhoea as predominant cause of IDA). Most of these IDA-related diagnoses were made in the subgroup of patients who received early endoscopic evaluation.

The majority of patients who did not receive early endoscopic evaluation did not have an IDA-related cause defined during the extended follow-up. To our knowledge, this has not been described in detail before.

Although the majority of patients with IDA without endoscopic evaluation have no IDA-related diagnosis during follow-up, a third of the patients with a late IDArelated cause were diagnosed with a GI malignancy, and an additional $11 \%$ had a strong suspicion of GI malignancy.

Table 4 Cox proportional-hazards survival analysis for patients diagnosed with colorectal cancer

\begin{tabular}{|c|c|c|c|c|c|c|}
\hline & \multirow{3}{*}{$\begin{array}{l}\text { Deceased } \\
\mathrm{n}=19(31 \%)\end{array}$} & \multirow{3}{*}{$\begin{array}{l}\text { Alive } \\
\mathrm{n}=42(69 \%)\end{array}$} & \multicolumn{2}{|l|}{ Univariable analysis } & \multirow{2}{*}{\multicolumn{2}{|c|}{ Multivariable analysis }} \\
\hline & & & & & & \\
\hline & & & HR $(95 \% \mathrm{Cl})$ & $P$ value & HR $(95 \% \mathrm{Cl})$ & $P$ value \\
\hline Age, median (range) & $78(50-87)$ & $73(52-89)$ & 1.06 (1.00 to 1.12$)$ & 0.063 & 1.10 (1.02 to 1.19$)$ & 0.017 \\
\hline \multicolumn{7}{|l|}{ Gender } \\
\hline Male & $8(13 \%)$ & $20(33 \%)$ & 0.77 (0.31 to 1.93$)$ & 0.582 & 1.58 (0.57 to 4.36$)$ & 0.377 \\
\hline Female & $11(18 \%)$ & $22(36 \%)$ & Reference group & & Reference group & \\
\hline \multicolumn{7}{|l|}{ Time to diagnosis } \\
\hline Early & $13(21 \%)$ & $36(59 \%)$ & $0.32(0.12$ to 0.87$)$ & 0.026 & 0.30 (0.09 to 1.02$)$ & 0.053 \\
\hline Late & $6(10 \%)$ & $6(10 \%)$ & Reference group & & Reference group & \\
\hline TNM stage & & & & 0.003 & & $<0.001$ \\
\hline I & $1(2 \%)$ & $11(18 \%)$ & Reference group & & Reference group & \\
\hline II & $3(5 \%)$ & $13(21 \%)$ & 3.23 (0.32 to 32.97$)$ & 0.323 & 3.47 (0.33 to 36.75$)$ & 0.302 \\
\hline III & $5(8 \%)$ & $12(20 \%)$ & 4.16 (0.48 to 35.97$)$ & 0.195 & 5.35 (0.57 to 49.94$)$ & 0.141 \\
\hline IV & $10(16 \%)$ & $5(8 \%)$ & 24.31 (2.78 to 212.41$)$ & 0.004 & 80.15 (7.47 to 859.67$)$ & $<0.001$ \\
\hline Unknown & - & $1(2 \%)$ & NA & NA & NA & NA \\
\hline
\end{tabular}

NA, not applicable. 
These diagnoses might represent missed opportunities at the time of IDA diagnosis and should alert GPs in their aim to unravel the underlying cause of IDA. Based on our study results, omitting early endoscopic evaluation in patients with IDA is not safe. As also has been described in several guidelines before, endoscopic evaluation should be performed in all patients aged 50 years and older with a new diagnosis of IDA. ${ }^{911}$

We observed $8 \%$ of CRC diagnoses within 18 weeks of finding IDA in our cohort, whereas $2 \%$ of patients received this diagnosis during follow-up. Comparison of these results with previous data on patients with IDA in general practice revealed a slight increase in early diagnoses and a decrease in delayed diagnoses ${ }^{67}$ This might be due to the comment that was added to the laboratory results alerting GPs to an endoscopic evaluation in patients with IDA. Furthermore, we offered participating GPs fast-track places for endoscopic evaluation, which may have led to earlier endoscopic evaluations.

Although the association between early versus late CRC diagnosis and mortality was not statistically significant in our data, the point estimate and its $95 \%$ CI were in line with previous studies in which early colonoscopy significantly increased overall survival in patients with CRC diagnosis. ${ }^{14}{ }^{15}$ The estimated association was adjusted for the TNM classification of the tumour at the time of diagnosis. Apparently, early-stage disease is important for better survival rates, and early CRC diagnosis, regardless of TNM classification, is too. This might be due to a better clinical condition at the moment of CRC diagnosis and start of treatment.

Finally, it was observed that in patients with IDA most early CRC diagnoses were right sided (84\%) possibly caused by the absence of GI complaints such as rectal bleeding. ${ }^{16}$ This lack of complaints may allow tumours to bleed unnoticed for a longer time, resulting in a diagnosis of IDA before the CRC is found. During our study period, $34 \%$ of all CRC diagnoses in the whole Dutch population were right sided according to the Netherlands Comprehensive Cancer Organization (data not shown). ${ }^{10}$ Our results support the suspicion that right-sided tumours are more frequently encountered in patients with IDA. ${ }^{916}$

\section{Implications for clinicians}

The majority of patients with IDA in general practice do not have an IDA-related cause defined during extended follow-up. However, endoscopic evaluation for all patients with IDA is justified since these patients are at increased risk for, in particular, right-sided CRC. Importantly, patients with IDA in general practice with a delayed diagnosis of CRC might risk decreased overall survival.

\section{Author affiliations}

${ }^{1}$ Internal Medicine, Albert Schweitzer Hospital Location Dordwijk, Dordrecht, The Netherlands

${ }^{2}$ Clinical Chemistry, Albert Schweitzer Hospital Location Dordwijk, Dordrecht, The Netherlands

${ }^{3}$ General practice, General practice van Houten, Hendrik-Ido-Ambacht, The Netherlands
${ }^{4}$ Biostatistics, Erasmus MC, Rotterdam, The Netherlands

${ }^{5}$ Gastro-enterology, Albert Schweitzer Hospital Location Dordwijk, Dordrecht, The Netherlands

${ }^{6}$ General Practice, Erasmus Medical Center, Rotterdam, The Netherlands

Acknowledgements The authors thank the participating GPs for their contribution to this study. Furthermore, the authors thank the registration team of the Netherlands Comprehensive Cancer Organization (IKNL) for the collection of data for the Netherlands Cancer Registry as well as the IKNL staff for scientific advice.

Contributors M-DL and JR conceived of the presented study design. AS, PJEB and $\mathrm{M}-\mathrm{DL}$ designed the study protocol. AS and KS collected the information. AS and JvR conducted the statistical analysis. RvH and FW were mainly involved in the clinical interpretation and legibility of the manuscript. All authors contributed to the clinical interpretation and writing process of the study results.

Funding This work was supported by a grant from the Friends Foundation and Leerhuis of the Albert Schweitzer Hospital, Dordrecht, the Netherlands.

Disclaimer None of the funders had any role in the design and conduct of the study; collection, analysis and interpretation of the data; and preparation, review or approval of the manuscript.

Competing interests None declared.

Patient consent for publication Not required.

Ethics approval This study was approved by the institutional review board of the Albert Schweitzer Hospital and was conducted in accordance with the Declaration of Helsinki.

Provenance and peer review Not commissioned; externally peer reviewed.

Data availability statement Data are available on reasonable request. All data relevant to the study are included in the article or uploaded as online supplementary information.

Open access This is an open access article distributed in accordance with the Creative Commons Attribution Non Commercial (CC BY-NC 4.0) license, which permits others to distribute, remix, adapt, build upon this work non-commercially, and license their derivative works on different terms, provided the original work is properly cited, appropriate credit is given, any changes made indicated, and the use is non-commercial. See: http://creativecommons.org/licenses/by-nc/4.0/.

\section{ORCID iD}

Annemarie Schop http://orcid.org/0000-0002-9786-2672

\section{REFERENCES}

1 loannou GN, Rockey DC, Bryson CL, et al. Iron deficiency and gastrointestinal malignancy: a population-based cohort study. Am J Med 2002;113:276-80.

2 Goddard AF, James MW, Mclntyre AS, et al. Guidelines for the management of iron deficiency anaemia. Gut 2011;60:1309-16.

3 James MW, Chen C-M, Goddard WP, et al. Risk factors for gastrointestinal malignancy in patients with iron-deficiency anaemia. Eur J Gastroenterol Hepatol 2005;17:1197-203.

4 Rockey DC, Cello JP. Evaluation of the gastrointestinal tract in patients with iron-deficiency anemia. N Engl J Med Overseas Ed 1993;329:1691-5.

5 Short MW, Domagalski JE. Iron deficiency anemia: evaluation and management. Am Fam Physician 2013;87:98-104.

6 Droogendijk J, Beukers R, Berendes PB, et al. Screening for gastrointestinal malignancy in patients with iron deficiency anemia by general practitioners: an observational study. Scand J Gastroenterol 2011;46:1105-10.

7 Yates JM, Logan ECM, Stewart RM. Iron deficiency anaemia in general practice: clinical outcomes over three years and factors influencing diagnostic investigations. Postgrad Med J 2004;80:405-10.

8 Schop A, Kip MM, Stouten K, et al. The effectiveness of a routine versus an extensive laboratory analysis in the diagnosis of anaemia in general practice. Ann Clin Biochem 2018;55:535-42.

9 Van Wijk MAM, Mel M, Muller PA, et al. Nederlands Huisartsen Genootschap-standaard Anemie. [Dutch general practitioners society Guideline anaemia]. Huisarts Wet 2003;46:21-9.

10 Netherlands Comprehensive Cancer Organization. Bewegingsinterventies hebben gunstig effect OP verminderen vermoeidheid, 2018. Available: https://www.iknl.nl/home 
11 Poston GJ, Tait D, O'Connell S, et al. Diagnosis and management of colorectal cancer: summary of NICE guidance. BMJ 2011;343:d6751-4.

12 Clere-Jehl R, Schaeffer M, Vogel T, et al. Upper and lower gastrointestinal endoscopies in patients over 85 years of age. Medicine 2017;96:e8439-7.

13 Netherlands comprehensive cancer organization. Cijfers over kanker [Numbers about cancer], 2018. Available: https://www. cijfersoverkanker.nl
14 Teng C-LJ, Yu J-T, Chen Y-H, et al. Early colonoscopy confers survival benefits on colon cancer patients with pre-existing iron deficiency anemia: a nationwide population-based study. PLoS One 2014:9:e86714-6.

15 Alonso-Abreu I, Alarcón-Fernández O, Gimeno-García AZ, et al. Early colonoscopy improves the outcome of patients with symptomatic colorectal cancer. Dis Colon Rectum 2017:60:837-44.

16 Lee GH, Malietzis G, Askari A, et al. Is right-sided colon cancer different to left-sided colorectal cancer? - a systematic review. Eur J Surg Oncol 2015;41:300-8. 